\title{
Antler and Body Size in Black-Tailed Deer: An Analysis of Cohort Effects
}

\author{
Johanna C. Thalmann, ${ }^{1}$ R. Terry Bowyer, ${ }^{1}$ Ken A. Aho, ${ }^{1}$ \\ Floyd W. Weckerly, ${ }^{2}$ and Dale R. McCullough ${ }^{3}$ \\ ${ }^{1}$ Department of Biological Sciences, Idaho State University, 921 South 8th Avenue, Stop 8007, Pocatello, ID 83209, USA \\ ${ }^{2}$ Department of Biology, Texas State University, 601 University Drive, San Marcos, TX 78666, USA \\ ${ }^{3}$ Department of Environmental Science, Policy, \& Management, University of California, Berkeley, 130 Mulford Hall No. 3114, \\ Berkeley, CA 94720, USA \\ Correspondence should be addressed to Johanna C. Thalmann; thaljoha@isu.edu
}

Received 5 August 2015; Revised 26 October 2015; Accepted 4 November 2015

Academic Editor: Sveinn Are Hanssen

Copyright (C) 2015 Johanna C. Thalmann et al. This is an open access article distributed under the Creative Commons Attribution License, which permits unrestricted use, distribution, and reproduction in any medium, provided the original work is properly cited.

For long-lived species, environmental factors experienced early in life can have lasting effects persisting into adulthood. Large herbivores can be susceptible to cohort-wide declines in fitness as a result of decreases in forage availability, because of extrinsic factors, including extreme climate or high population densities. To examine effects of cohort-specific extrinsic factors on size of adults, we performed a retrospective analysis on harvest data of 450 male black-tailed deer (Odocoileus hemionus columbianus) over 19 years in central California, USA. We determined that population density of females had a more dominant effect than did precipitation on body size of males. Harvest of female deer resulted in increases in the overall size of males, even though a 6-year drought occurred during that treatment period. Body size was most influenced by female population density early in life, while antler size was highly affected by both weather early in life and the year directly before harvest. This study provides insights that improve our understanding of the role of cohort effects in body and antler size by cervids; and, in particular, that reduction in female population density can have a profound effect on the body and antler size of male deer.

\section{Introduction}

Climate and population density influence organisms throughout their lives and often lead to phenotypic variation among cohorts. Cohort effects occur when individuals born within the same year experience similar environmental conditions, which may alter the life-history characteristics of that group [1]. Large mammalian herbivores, in particular, are strongly influenced by local weather, because of direct effects of weather on forage [2-4]. Rainfall increases the quality and quantity of vegetation [5], which has a positive influence on body size of some ungulates [6-8]. Body size is affected more easily by variation in the environment when a population is at moderate to high densities [7-11], because of increased intraspecific competition for food [12].

Understanding how the interaction between climate and population density influences body mass throughout the lifetime of a large herbivore enables biologists to better predict growth, survival, and reproduction within cohorts [13-17]. Extrinsic and intrinsic factors affect body condition, and when resources are limited, important tradeoffs may be made early in life by an individual, or by a mother before parturition, which affects offspring while in utero [18]. Those tradeoffs result in delayed life-history characteristics that can persist into adulthood and even through future generations [4].

In times of severe weather or high population density, tradeoffs are made by the mother when the fetus is in utero [19]. Decreases in maternal investment during periods of low spring precipitation stunt the growth of fetuses, resulting in young that are born small and remain small throughout their lives [20-26]. Furthermore, much of the variation in adult size of ungulates has been linked to conditions experienced during the year of birth [27] and environmental conditions and nutrition of their grandmothers 2 generations previously $[3,28]$. 
Antler size has been positively correlated with warmer temperatures and higher precipitation in spring and autumn during the year of harvest [29]. Discerning the influence of extrinsic factors the year preceding harvest with those that occurred during youth is critical for understanding phenotypic variation in size of antlers. Determining the degree to which weather and population density during youth and adulthood affect antler and body size of ungulates is still poorly understood, although body and antler size are related to a number of life-history characteristics among cervids [30].

We conducted a retrospective analysis of harvest data [31] to examine effects of environmental conditions on antler and body size within and across cohorts of a population of blacktailed deer (Odocoileus hemionus columbianus) from 1980 to 1997. We hypothesized that cohort effects would influence body and antler size of male black-tailed deer. Specifically, we predicted that high annual precipitation during gestation, during the first year of growth, and during the year of harvest would be related to body and antler size. Temperatures that were low in summer and high in winter during those periods were predicted to positively affect body size of males. Also, we predicted that a decrease (brought about by harvest) in female population density during gestation, and 1 year following parturition, would result in greater body and antler size of males at the time of harvest. Understanding how a single year of environmental factors affects life-history characteristics of multiple generations can lead to improvements in predicting body growth and antler size, as well as providing insights into conserving and managing those large herbivores.

\section{Methods}

Research by McCullough [31] was conducted at the Hopland Research and Extension Center (hereafter Hopland) of the University of California $\left(38^{\circ} 58^{\prime} \mathrm{N}, 123^{\circ} 08^{\prime} \mathrm{W}\right)$. The 2,149 ha area is located in Mendocino County, about $170 \mathrm{~km}$ north of San Francisco, in the central portion of the coastal mountain ranges of California, USA. Hopland is characterized by a Mediterranean climate; mean summer and autumn temperatures range from 20 to $25^{\circ} \mathrm{C}$, and winters are mild with occasional frost in valley bottoms and infrequent light snow at high elevations $(>800 \mathrm{~m})$. Interannual rainfall was variable among years $(1979-1997 ; \bar{x}=96 \mathrm{~mm}$; range $=50-191 \mathrm{~mm}, \mathrm{CV}$ $=37 \%$ ), with a 6 -year drought occurring during the treatment period (1985-1991), where females were harvested (Figure 1).

Discrete seasons of vegetative growth and senescence were evident between 1979 and 1997, which followed seasonal patterns of precipitation $\left(F_{12,12}=2.69, P=0.01\right)$. Most precipitation occurred from October through April; rain seldom fell during May through September, which also was characterized by the warmest average monthly temperatures (Figure 2). Winters are usually mild and wet, encouraging herbaceous growth that extends from November through April. The percentage of vegetative cover changes as wet conditions shift towards the dry season, with an increase in annual grasses and decrease in forbs [2]. Common vegetation types on Hopland include oak woodlands (Quercus spp.), grasslands (e.g., Bromus spp., Erodium spp., and Festuca spp.), and chaparral (Adenostoma spp.) [32].

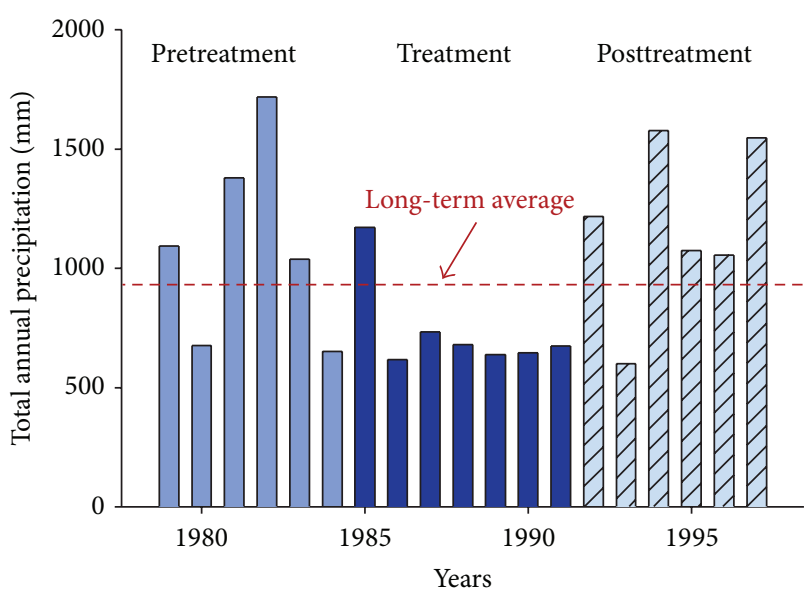

FIGURE 1: Total annual precipitation for all years of the study (19791997) is depicted for Hopland California, USA. Yearly precipitation was calculated from the start of July to the end of June of the following year. This arrangement allowed for the examination of a complete year of vegetative growth, in particular during the wet season (October-April). Darker blue represents the experimental years when both females and males were harvested $(\bar{x}=737.5 \mathrm{~mm}$, $\mathrm{SD}=26.22 \mathrm{~mm}$ ). Light blue is pretreatment (only male deer harvested) $(\bar{x}=1092.7 \mathrm{~mm}, \mathrm{SD}=24.38 \mathrm{~mm})$, and diagonal crosshatching represents posttreatment (only male deer harvested) $(\bar{x}=$ $1178.5 \mathrm{~mm}, \mathrm{SD}=48.69 \mathrm{~mm}$ ). The dark red dashed line identifies the long-term average annual precipitation $(\bar{x}=932.0 \mathrm{~mm}, \mathrm{SD}=$ $329.20 \mathrm{~mm}$ ).

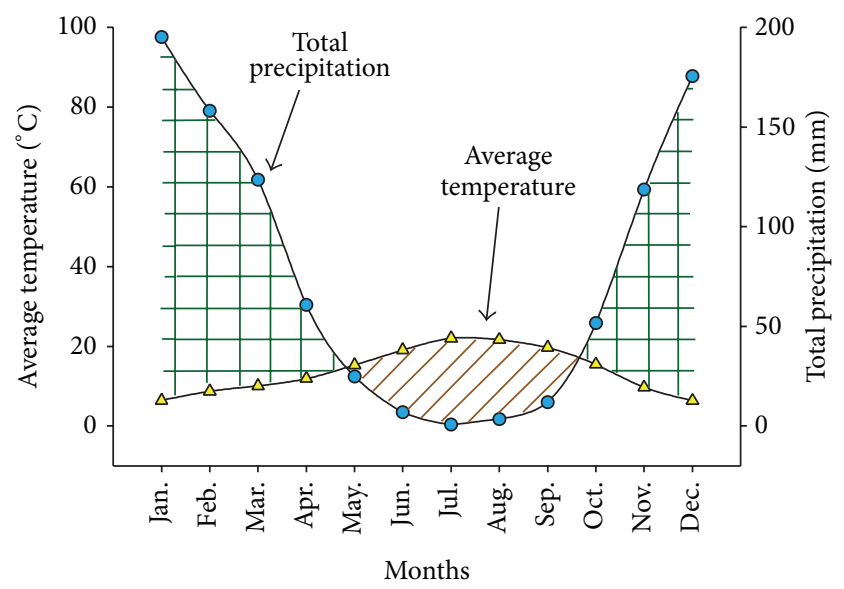

FIGURE 2: Climate graph illustrating the relationship between temperature and precipitation for Hopland, California, USA. Triangles represent average monthly temperature and circles depict average total monthly precipitation. Diagonal lines represent times of drought (May-September), whereas the cross pattern represents times of water surplus (October-April). Data were collected from a local weather station at Hopland from 1979 to 1997.

Domestic sheep (Ovis aries) were pastured on Hopland and maintained at a population size of 900-1,500 females throughout the study (1979-1997) [33]. Black-tailed deer were abundant and hunted annually. The prehunt population before the study began was estimated at 443 deer (25.9 deer $/ \mathrm{km}^{2}$ ) [31]. In 1991, at the end of the treatment period 
(female and male harvest), the population was approximately 250 deer $\left(14.6 \mathrm{deer} / \mathrm{km}^{2}\right)$. Predators of deer include bobcats (Lynx rufus), coyotes (Canis latrans), mountain lions (Puma concolor), and black bears (Ursus americanus). No attempt was made to control predators during the study.

2.1. Collection and Measurements of Deer. To determine if density-dependent effects influenced antler growth and body size of male black-tailed deer, we reanalyzed data collected by McCullough [31] from 1979 to 1997. No data were used from males sampled in 1979, however, because too few morphometric measurements were collected. During that study, there was a 7-year treatment period (1985-1991) where a mean of 24 females ( $\mathrm{SD}=4.6$ females) were harvested each year in addition to the annual harvest of males. Six years before and after the treatment period of female harvest, only male deer were killed ( $\sim 30$ males per year). The initial research by McCullough [31] was conducted under animal use protocols approved by the University of California, Hopland Research and Extension Center, and a memorandum of understanding and collecting permits from the California Fish and Game Commission.

In our analysis, we used weight, antler measurements, and estimated age from 450 male deer that were harvested during 1980-1997. Males were not included if they lacked data for age or multiple measurements of antlers. When only a single antler measurement (diameter or length of either the right or left antlers) was missing, data were interpolated $(n=49)$ from the complete data set. We used the regression function in the R 3.1.2 statistical environment $[34,35]$ to determine those values. Dressed weight was used in place of whole-body weight because whole weights were not recorded from 1991 to 1997. We used this approach because dressed and whole-body weights [36] of black-tailed deer exhibited a strong positive relationship $\left(r^{2}=0.91, P<0.001, \hat{y}=6.5573+1.739 x\right)$. Moreover, carcass weight in mule deer (O.h. hemionus) is strongly correlated with other body measurements, including chest girth, body length, head length, and mandible length [37]. From 1980 to 1997, deer were aged from either cementum annuli or tooth eruption and wear [38]. Data on cementum annuli were used for aging deer during years where both types of data were available. We were able to use both types of data because age determined from cementum annuli and tooth eruption and wear was positively related $\left(r^{2}=0.63\right.$, $P<0.001, \hat{y}=0.1589+1.0303 x)$. Aging black-tailed deer based on tooth eruption and wear is highly accurate through 2.5 years of age. Approximately $73 \%$ of deer 3.5 to $\geq 5.5$ years of age were categorized correctly with a tendency to underestimate ages [39].

To reduce the number of variables, a Principal Component Analysis (PCA) based on the covariance matrix was conducted on antler measurements (right and left diameter and length, and spread) collected by McCullough [31]. Spread and length were measured to the nearest $6.4 \mathrm{~mm}$, and diameters were measured to the nearest $0.5 \mathrm{~mm}$. The number of left and right antler tines (points) was not included in the PCA, because of problems associated with the use of a small range of meristic characters to estimate phenotypic development [40]. The proportion of variance explained by the PCA was nearly identical between the whole raw data set (0.886) and with the addition of interpolated values $(0.880)$; consequently, we included the interpolated values to increase sample size $(n=450)$. PC1 for antler measurements had negative loadings, with larger antlers represented by negative values and smaller antlers by positive values. The proportion of variance explained by $\mathrm{PCl}$ was 0.76 . Loadings for antler measurements were similar (Table 2), indicating that $\mathrm{PC1}$ was a reliable measure of antler size $[41,42]$. We multiplied the principal components by negative 1 for all analyses so positive values represented larger antlers, making results more logical to follow.

Age is related to antler and body size in male cervids [43, 44]. We fitted the Von Bertalanffy growth curve to examine the relationship between body size and age in male blacktailed deer using the package Fishmethods [45] in R $[46,47]$. This procedure also provided the best fit for the relation between age and antler size (PC1), because we had few old individuals that might have resulted in a quadratic curve [42]. Residuals were obtained for both antler and body size, which corrected those size variables for age.

2.2. Local Weather. We determined effects of extrinsic factors on body weight and antler size of males by compiling local weather data. Total precipitation and average temperature were collected at Hopland each month. Monthly average temperatures and total monthly precipitation were compared in a Walter climate graph (Figure 2) to distinguish seasons of vegetative growth (October through April) and times of water deficit (May through September) [48].

Periods for which weather data were considered in models included gestation by the mother while the male was in utero (October through April); the first year of growth by the male offspring (May through April); and the weather during the year before harvest (October the previous year through September). For both the first year of growth and the year before harvest, we divided those periods into wet (October through April) and dry (May through September) seasons for a clearer understanding of how temperature and precipitation influenced deer. For instance, weather variables that would be included in data for a male deer harvested at 3.5 years of age in autumn of 1990 would include weather experienced while in utero during gestation by the mother (October 1986 through April 1987), the dry season of the first year of growth by the male (May 1987 through September 1987), the wet season of the first year of growth by the male (October 1987 through April 1988), the wet season of the year preceding harvest (October 1989 through April 1990), and the dry season of the year preceding harvest of the male (May 1990 through September 1990). Although the last third of gestation is the most energetically expensive for large mammalian females [49], weather during full gestation was used in our analyses, because female body condition affects the offspring throughout its time in utero. Furthermore, female deer inhabiting a Mediterranean ecosystem must build sufficient body reserves early in gestation, because parturition occurs at the beginning of the dry season when vegetation starts to senesce $[2,50]$. 


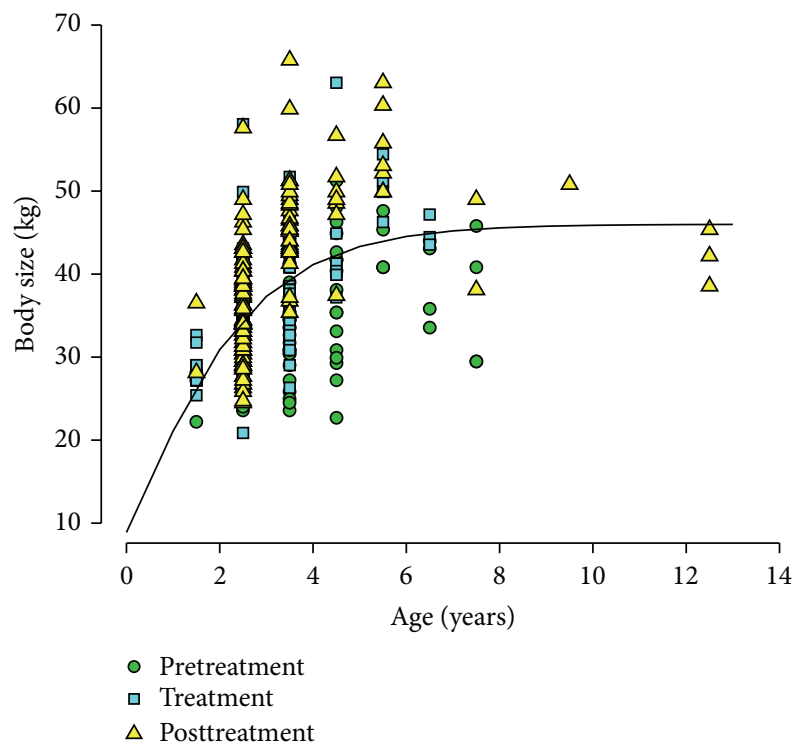

FIgURE 3: The Von Bertalanffy growth curve depicts age at mean asymptotic body mass of male black-tailed deer during the study. Pretreatment, treatment, and posttreatment categories represent the period when males were harvested in Hopland, California, USA, from 1980 to 1997.

2.3. Statistical Analyses. Intrinsic factors (body and antler size) were modeled as dependent variables in $\mathrm{R}$ [34] against extrinsic variables that included treatment period (pretreatment and combined treatment and posttreatment) and total monthly precipitation and average monthly temperature for each time period (i.e., in utero, the dry season during the first year of growth, the wet season during the first year of growth, the wet season before harvest, and the dry season before harvest). Treatment and posttreatment were combined into a single period because of lingering density-dependent factors after 7 years of female harvest. An interaction term between precipitation and population density was added to models. Body weight corrected for age was included as a variable in the antler-size model, because higher body reserves would allow the male to invest more in antler growth [41, 42]. Contrarily, antler size was omitted from the body-size model because antler growth is less likely to affect body size. Colinearity was examined for all variables with variance inflation factors (VIF) in $\mathrm{R}$ package Car [51]. All continuous quantitative variables had VIF values $\leq 5$ indicating that multicolinearity did not bias our models [52]. We used the package MuMIn [53] in R to dredge and average the top models based on all models with values $\leq 2$ using Akaike's information criterion for small samples (AICc) of the top model [54]. Confidence intervals for model-averaged parameters were lowered to $85 \%$ to more closely conjoin the information theoretic approach of AICc to most frequentist confidence intervals. In particular, holding likelihood constant, AICc will increase by $2 d$, where $d$ is the number of added parameters in a model. Thus, just as $P\left(\chi_{1}^{2} \leq\right.$ $\left.1.96^{2}\right) \approx 0.95$, where $\chi_{1}^{2}$ is a chi-square distribution with one degree of freedom, it is also true that $P\left(\chi_{1}^{2} \leq 2\right) \approx 0.85$

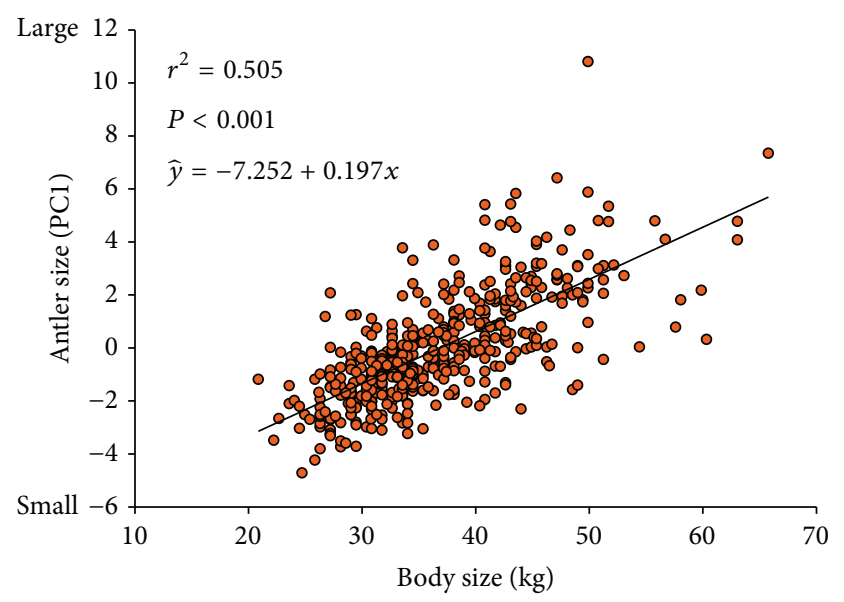

FIGURE 4: Body weight compared with antler size for male blacktailed deer during 1980-1997, Hopland, California, USA.

[55]. We used multiple lines of inquiry to make the most informed decision about which variables were most influential in determining body weight or antler size. We examined $85 \%$ confidence intervals, and the relative importance of each variable, calculated as a sum of the Akaike weights over all of the models in which a particular parameter appeared. To further understand how a reduction in female population density affected antler and body size, we performed the median test [56]. We compared the median before and after female harvest began with the median for the entire study.

\section{Results}

We performed a retrospective analysis on data for 450 blacktailed deer, harvested between 1980 and 1997 at the Hopland Research Extension Center. Male black-tailed deer, on average, weighed $36.9 \mathrm{~kg}$. Asymptotic body mass, determined from Von Bertalanffy growth equation, was $46 \mathrm{~kg}$ at 5.5 years of age $\left(L_{t}=46.005\left(1-e^{-0.6117}(t+1.4106)\right), r^{2}=0.26\right.$; Figure 3$)$. To account for the relationship between age and body and antler size, residuals from the Von Bertalanffy growth curve were used in subsequent analyses (Figure 3). Dressed weight and antler size (PC1) also were positively related (Figure 4), but to better understand changes in size of male deer, we examined those variables separately.

Body size of male deer increased during the study (Figure 5(a), Table 1). Body size (i.e., dressed weight corrected for age) increased profoundly after the treatment period but was highly variable among individuals $(\hat{y}=0.44 x-877.60$, $r^{2}=0.13, P<0.001$; Figure 5(a)).

Deer harvested after the treatment period began were significantly larger than those harvested during the pretreatment period. When corrected for age, 180 of 323 male deer harvested after the treatment period had a body weight greater than the median for the entire sample size $(n=450$; $\left.\chi^{2}=14.22, P>0.001\right)$. Through the study, growth rate and asymptotic body weight of male deer rose from pretreatment (0.908 per year; $38.7 \mathrm{~kg}$ ) to posttreatment period (1.22 per 


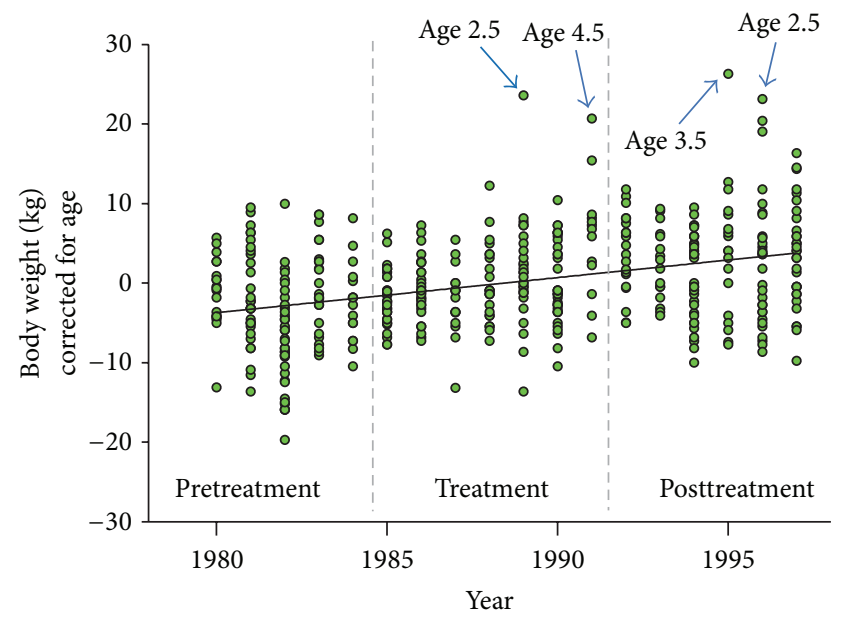

(a)

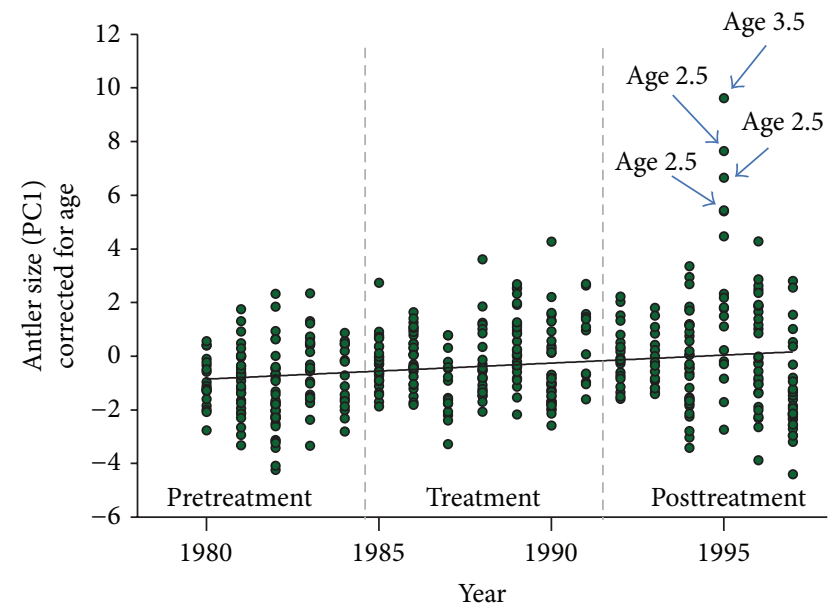

(b)

FIGURE 5: Trends in size of male black-tailed deer in Hopland, California, USA. (a) The increase in body size (dressed weight corrected for age) between years. (b) The increase in antler size (principle component 1 corrected for age) through time. Sections are partitioned by pretreatment (only males harvested, 1980-1984), treatment (both males and females harvested, 1985-1990), and posttreatment (only males harvested, 1991-1997). Arrows point to the four largest individual males and identify the age of each male at time of harvest.

TABLE 1: Characteristics of male black-tailed deer for each treatment period from 1980 to 1997 harvested at Hopland, California, USA. The number of male deer per sampling period only represents males that were used in our analyses.

\begin{tabular}{|c|c|c|c|c|}
\hline Sampling period & Characteristics & Mean & Standard deviation & Range \\
\hline \multirow{3}{*}{$\begin{array}{l}\text { Male harvest only } \\
\text { (pretreatment: } 1980-1984) \\
(n=127)\end{array}$} & Antler size (PC1) & -0.41 & 1.57 & -3.41 to 4.30 \\
\hline & Dressed weight $(\mathrm{kg})$ & 34.76 & 6.72 & 6.42 to 51.26 \\
\hline & Age (years) & 3.40 & 1.30 & 1.50 to 7.50 \\
\hline \multirow{3}{*}{$\begin{array}{l}\text { Male and female harvest } \\
\text { (treatment: 1985-1991) } \\
(n=162)\end{array}$} & Antler size (PC1) & 0.0 & 1.61 & -2.86 to 4.72 \\
\hline & Dressed weight $(\mathrm{kg})$ & 36.08 & 6.45 & 6.45 to 63.05 \\
\hline & Age (years) & 2.90 & 0.89 & 1.50 to 6.50 \\
\hline \multirow{3}{*}{$\begin{array}{l}\text { Male harvest only } \\
\text { (posttreatment: 1992-1997) } \\
(n=161)\end{array}$} & Antler size (PC1) & 0.35 & 2.46 & -4.40 to 10.22 \\
\hline & Dressed weight $(\mathrm{kg})$ & 39.55 & 8.44 & 8.44 to 65.77 \\
\hline & Age (years) & 3.30 & 1.72 & 1.50 to 12.50 \\
\hline
\end{tabular}

year; $446.4 \mathrm{~kg})\left(L_{t}=38.744\left(1-e^{-0.908}(t-0.062)\right), r^{2}=0.18\right.$ $L_{t}=46.424\left(1-e^{-1.225}(t-0.039)\right), r^{2}=0.45$, resp. $)$.

Antler size (PC1) increased slightly during the study $(\hat{y}=$ $0.06 x-118.93, r^{2}=0.04, P<0.001$; Figure 5(b); Table 1). Overall, antler size increased with age (Figure $6, L_{t}=2.82(1-$ $\left.\left.e^{-0.4611}(t-2.931)\right), r^{2}=0.28\right)$, and when size was corrected for age, the difference in the number of deer with antlers larger than the grand median was significantly greater after female harvest began, compared with pretreatment $\left(\chi^{2}=6.32, P=\right.$ 0.012 ). When both high precipitation and low female density occurred simultaneously, there were substantial increases in size of antlers, such as those observed in males harvested in 1995 (Figures 1 and 5(b)).

For models of both antler size and body weight, extrinsic variables incorporated into each model included an index for population density (reflected by treatment period), and temperature and precipitation during critical periods of time for growth of body and antlers in male deer (Tables 2 and 3).
In our model for body size (dressed weight corrected for age), 16 competing models were averaged (Table 2). Two variables were determined to be the best predictors of body weight from $85 \%$ confidence intervals and summed Akaike weights (Table 4 ). The most significant variable was female population density during the gestation by the mother while the male was in utero, but only after female harvest began in 1985 (treatment and posttreatment periods combined). The interaction between weather, specifically precipitation, and treatment period when the male was in utero was important in predicting body size of male deer. Although 85\% CI overlapped zero, population density interacted with precipitation during the first year of growth.

We identified and averaged 17 competing models explaining antler size ( $\mathrm{PCl}$ corrected for age) (Table 3 ). Five variables were influential in determining antler size (Table 5). Those variables had a relative importance of 1 when Akaike weights were summed and were different from 0 when we examined 
TABLE 2: Component models for body size. Term codes: A: average temperature during the wet season of the first year of growth, $\mathrm{B}$ : total precipitation during the wet season before harvest, C: average temperature during the dry season before harvest, $\mathrm{D}$ : average temperature during the wet season before harvest, E: total precipitation while the male was in utero during the gestation by the mother, F: average temperature while the male was in utero during the gestation by the mother, G: treatment period (index for population density) while the male was in utero during the gestation by the mother, $\mathrm{H}$ : treatment period (index for population density) during the first year of growth, I: total precipitation during the dry season of the first year of growth, J: average temperature during the dry season of the first year of growth, K: interaction term between precipitation and treatment during gestation by the mother, and $\mathrm{L}$ : interaction term between precipitation and treatment during the dry season of the first year of growth. Data for these models was from harvested black-tailed deer from Hopland, California, USA, from 1980 through 1997.

\begin{tabular}{lccccc}
\hline Model & df & logLik & AICc & $\Delta$ & Weight \\
\hline E, G, H, I, K, L & 8 & -1437.13 & 2890.59 & 0.00 & 0.11 \\
A, E, G, H, I, K, L & 9 & -1436.20 & 2890.81 & 0.22 & 0.1 \\
B, E, G, H, I, K, L & 9 & -1436.24 & 2890.88 & 0.29 & 0.09 \\
A, B, E, G, H, I, K, L & 10 & -1435.27 & 2891.05 & 0.46 & 0.08 \\
B, D, E, G, H, I, K, L & 10 & -1435.60 & 2891.70 & 1.11 & 0.06 \\
A, B, D, E, G, H, I, K, L & 11 & -1434.55 & 2891.71 & 1.12 & 0.06 \\
C, E, G, H, I, K, L & 9 & -1436.68 & 2891.78 & 1.19 & 0.06 \\
A, C, E, G, H, I, K, L & 10 & -1435.68 & 2891.86 & 1.27 & 0.06 \\
A, E, G, H, I, J, K, L & 10 & -1435.71 & 2891.91 & 1.32 & 0.05 \\
A, C, D, E, G, H, I, K, L & 11 & -1434.70 & 2892.00 & 1.41 & 0.05 \\
D, E, G, H, I, K, L & 9 & -1436.81 & 2892.03 & 1.44 & 0.05 \\
A, D, E, G, H, I, K, L & 10 & -1435.83 & 2892.16 & 1.57 & 0.05 \\
A, B, E, G, H, I, J, K, L & 11 & -1434.79 & 2892.18 & 1.58 & 0.05 \\
C, D, E, G, H, I, K, L & 10 & -1435.84 & 2892.19 & 1.60 & 0.05 \\
A, E, F, G, H, I, K, L & 10 & -1435.99 & 2892.48 & 1.89 & 0.04 \\
E, G, H, I, J, K, L & 9 & -1437.07 & 2892.56 & 1.97 & 0.04 \\
\hline
\end{tabular}

$85 \%$ confidence intervals. The variable that most positively influenced antler size was body weight corrected for age. Temperature was highly influential during three critical periods of time. All temperature variables exhibited a negative trend with antler size of male deer. The periods in which temperature was most important included, in descending order of significance, the dry season directly before harvest, during the wet season during the first year of growth, and during the wet season the year of harvest. A negative interaction occurred between precipitation and population density (indexed by treatment period) after 1985, which significantly affected antler size. Even though the 85\% CI overlapped zero, female population density while the male was in utero had a significant positive trend in determining antler size, but only after female harvest began in 1985 (treatment and posttreatment periods combined).

\section{Discussion}

We demonstrated that cohort effects could have profound influences on body and antler size of male black-tailed deer,

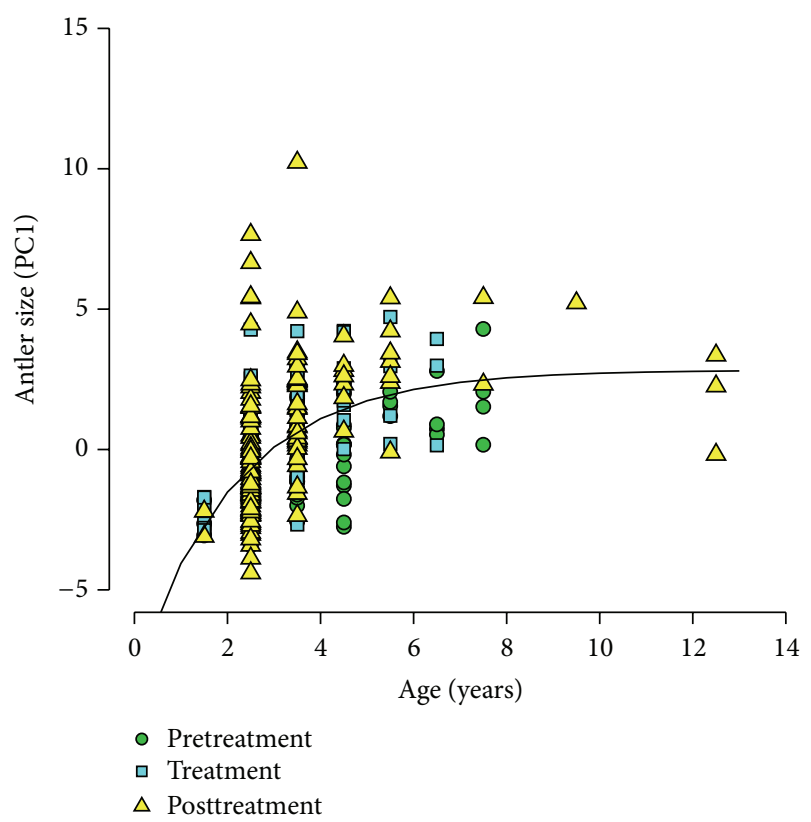

FIGURE 6: The Von Bertalanffy growth curve depicts the relation between age and antler size of male black-tailed deer during the study. Pretreatment, treatment, and posttreatment categories represent the period when males were harvested in Hopland, California, USA, from 1980 to 1997.

but climatic and density-dependent factors affected those variables differently. We predicted that a reduction in female population density while the male was in utero and during his first year of growth would lead to increases in size of body and antlers of male deer. Following our prediction, treatment period, an index to female population density, was a significant predictor of body size. Specifically, female population density after 1985 (after female harvest had begun - treatment and posttreatment combined) was positively related to body size of male deer at time of harvest. Female density during the first year of growth of the male was an important predictor of the body size of male deer at time of harvest. Notably, younger ( $\sim 3$ years of age) males harvested during posttreatment had larger antlers and obtain heavier body weight than older males (8-12 year olds), which were reared during a time of high female population densities (Figures 3 and 5(a)). Intraspecific competition between females and young likely was high early in the study, reducing the energy available for females to invest in offspring, probably stunting the growth of males early in life. Other studies also have documented that cervids born small remain small as adults, even when conditions are favorable later in life [3].

We predicted that high annual precipitation during critical periods for growth (while in utero, during the first year of growth, and during the year of harvest) would positively affect body and antler size of males. Contrary to our prediction, precipitation by itself had little influence on either body or antler size. Only for the antler size model did precipitation, specifically during the first summer of life, have strong predictive power. 
TABle 3: Component models for antler size (PC1). Term codes: A: average temperature during the wet season of the first year of growth, B: total precipitation during the dry season before harvest, C: total precipitation during the wet season before harvest, D: average temperature during the dry season before harvest, E: weight corrected for age (residuals), F: total precipitation while the male was in utero during the gestation by the mother, G: average temperature while the male was in utero during the gestation by the mother, $\mathrm{H}$ : treatment period (index for population density) while the male was in utero during the gestation by the mother, I: treatment period (index for population density) during the first year of growth, J: total precipitation during the dry season of the first year of growth, $\mathrm{K}$ : total precipitation during the wet season of the first year of growth, L: average temperature during the dry season of the first year of growth, $\mathrm{M}$ : interaction term between precipitation and treatment during the wet season of the first year of growth, $\mathrm{N}$ : interaction term between precipitation and treatment during the wet season of the first year of growth. Data for these models was from harvested black-tailed deer from Hopland, California, USA, from 1980 through 1997.

\begin{tabular}{lccccc}
\hline Model & df & logLik & AIC & $\Delta$ & Weight \\
\hline A, D, E, F, H, I, K & 9 & -766.37 & 1551.15 & 0 & 0.11 \\
A, D, E, F, J, K, L, N & 10 & -765.54 & 1551.59 & 0.44 & 0.09 \\
A, C, D, E, F, J, K, L, N & 11 & -764.69 & 1551.98 & 0.82 & 0.07 \\
A, D, E, F, H, I, J, K, L, N & 12 & -763.68 & 1552.08 & 0.92 & 0.07 \\
A, D, E, F, H, J, K, L, N & 11 & -764.84 & 1552.28 & 1.12 & 0.06 \\
A, C, D, E, F, H, I, J, K, L, N 13 & -762.74 & 1552.32 & 1.16 & 0.06 \\
A, C, D, E, F, H, J, K, L, N & 12 & -763.81 & 1552.33 & 1.18 & 0.06 \\
A, D, E, F, J, L, N & 9 & -767.08 & 1552.57 & 1.41 & 0.05 \\
A, D, E, F, G, H, I, K & 10 & -766.05 & 1552.60 & 1.45 & 0.05 \\
A, C, D, E, F, H, I, K & 10 & -766.08 & 1552.67 & 1.51 & 0.05 \\
A, D, E, F, H, J, L, N & 10 & -766.09 & 1552.68 & 1.53 & 0.05 \\
A, D, E, F, H, I, K, L & 10 & -766.10 & 1552.71 & 1.55 & 0.05 \\
A, C, D, E, F, H, J, L, N & 11 & -765.22 & 1553.04 & 1.88 & 0.04 \\
A, D, E, F, H, I, K, M & 10 & -766.29 & 1553.09 & 1.93 & 0.04 \\
A, D, E, F, G, J, K, L, N & 11 & -765.25 & 1553.10 & 1.94 & 0.04 \\
A, B, D, E, F, J, K, L, N & 11 & -765.26 & 1553.12 & 1.96 & 0.04 \\
A, D, E, F, H, I, J, K & 10 & -766.32 & 1553.14 & 1.99 & 0.04 \\
\hline
\end{tabular}

Our results, however, did affirm that there was a significant interaction between precipitation and treatment period, revealed by the 6-year drought during the study. Indeed, that interaction between female population density and precipitation had a significant effect on both antler and body size of males. In the body-size model, there was a negative relation between precipitation during the gestation by the mother and female density after 1985 (after female harvest had begun and female population density was lower). Similarly, that interaction was significant in the model for antler size, but this time involving precipitation during the first year of growth by the male. A reasonable explanation for this result is the increased rainfall during 1994, which also corresponded with some of the lowest female densities following 7 years of female harvest. High precipitation alone did not result in large antler and body sizes documented during 1994 and 1995, because there was even more precipitation in 1982 and 1983 , yet deer were significantly smaller during those years.
Our models offer evidence that the positive effects of female harvest overrode negative influences of the drought and resulted in greater body weight and antler size, a conclusion also reached by McCullough [31].

As expected, temperature had a negative relation with size of male deer during three critical periods of timewhile in utero, during the first year of growth, and the year immediately before harvest. Increases in temperature during the wet season likely reduced snowpack at high elevations and hereby constrained late season forage by decreasing water availability in late spring from snowmelt. Late spring is a critical time for deer in a Mediterranean ecosystem, because females with young must lactate as forage senesces [50]. Unexpectedly, temperature variables only were strong predictors of antler size but not body weight. Male deer grow antlers from March through July [57], which coincides with some of the hottest temperatures, particularly during June and July (Figure 2). The negative relation ostensibly occurred because of effects of hot temperatures on the senescence of forage when antlers were still growing.

We faced several challenges in conducting this study. We were constrained in some analyses because of issues concerning missing data. First, we attempted to examine effects of the normalized difference vegetation index (NDVI) on body and antler growth of deer. Unfortunately, too few images were available because of cloud cover or missing scenes to make that assessment possible across years. Nevertheless, we observed positive correlations (data not shown) between weather variables and available NDVI scenes. During some years, there also was incomplete data on antler measurements of deer [31]. We dealt with this shortcoming by interpolating antler metrics for no more than one measurement for 49 of 450 deer, with few observable effects on results. Data from 1979 were too sparse and therefore not included in analyses. Moreover, data were not collected annually on population size, so we used an index for female population density by dividing the study into two categories-pretreatment compared with the combined treatment (female harvest) and posttreatment periods. Indeed, population density with respect to carrying capacity $(K)$ is reflected by female condition and reproduction [58]. We have no data on how selectivity of hunters for large males may have changed over the course of the study, but there is no obvious reason to believe it did.

Although female population size was not recorded during the study, three density-dependent patterns allowed us to infer that female density decreased sufficiently to allow for improvements in physical condition during the treatment period. First, females $<2$ years old were mistaken for older females because of their large body size [31], indicating that population densities were below $K$ and females were in good nutritional condition $[17,59,60]$. Pregnancy of females $<2$ years old also increased markedly during the treatment period [31]. Cementum annuli, induced by periods of annual stress, were more obscure after female harvest began [61]. McCullough [31] noted that those results indicated a higherquality diet, likely leading to improvements in body condition of females, which increased recruitment of young as well as the size of male offspring. 
TABLE 4: Model-averaged coefficients for body size of black-tailed deer during 1980-1997 in Hopland, California, USA. Abbreviations of model parameters are as follows: Precip: total monthly precipitation; Temp.: average monthly temperature; D: the dry season (May-September); W: the wet season (October-April); in_utero: the period during the full gestation of the mother (October-April); grow: the first year of growth of the male (May-April) split into wet and dry seasons; Harv: the year prior to harvest of the male (October-September) split into wet and dry seasons; Treat: the treatment period (before: pretreatment, or after: the combined treatment and posttreatment); Int: the interaction term between precipitation and treatment period during gestation by the mother or the first year of growth; Antler (PC1): the first principal component for antler size (large antlers are negative; small antlers are positive). Bold values in the confidence interval (CI) column represent parameters that did not overlap zero.

\begin{tabular}{|c|c|c|c|c|}
\hline Model parameter & Estimate & Std. error & Adjusted SE & $85 \% \mathrm{CI}$ \\
\hline (Intercept) & -13.2400 & 12.4900 & 12.5100 & -44.0232 to 16.8578 \\
\hline Precip_in_utero & 0.0004 & 0.0011 & 0.0011 & -0.0022 to 0.0027 \\
\hline Treat_in_utero [after] & 6.1000 & 1.9630 & 1.9680 & 0.7814 to 9.8699 \\
\hline Treat_grow [after] & -1.3070 & 2.0450 & 2.0500 & -5.3909 to 5.4570 \\
\hline Precip_grow_D & 0.0068 & 0.0214 & 0.0214 & -0.0302 to 0.0696 \\
\hline Int_treat_in_utero [after]_\&_precip & -0.0053 & 0.0021 & 0.0021 & -0.0094 to -0.0007 \\
\hline Int_treat_grow [after]_\&_precip_D & 0.0624 & 0.0293 & 0.0293 & -0.0046 to 0.1250 \\
\hline AvTem_grow_W & 0.8908 & 0.6205 & 0.6222 & -0.7813 to 2.2762 \\
\hline Harv_yr_P_W & 0.0013 & 0.0009 & 0.0009 & -0.0008 to 0.0033 \\
\hline Harv_yr_T_W & 0.1109 & 0.1026 & 0.1028 & -0.1261 to 0.3117 \\
\hline Harv_yr_T_D & 0.6407 & 0.5570 & 0.5584 & -0.6341 to 1.8067 \\
\hline Tem_grow_D & 0.5226 & 0.6734 & 0.6751 & -0.8858 to 1.7416 \\
\hline Tem_mom_gest & 0.3980 & 0.6185 & 0.6202 & -1.3374 to 1.3285 \\
\hline
\end{tabular}

TABLE 5: Model-averaged coefficients for antler size of black-tailed deer during 1980-1997 in Hopland, California, USA. Abbreviations of model parameters are as follows: Precip: total monthly precipitation; Temp: average monthly temperature; in_utero: the period while the male was in utero during the full gestation (October-April); D: the dry season (May-September); W: the wet season (October-April); grow: the first year of growth of the male (May-April) split into wet and dry seasons; Harv: the year prior to harvest of the male (October-September) split into wet and dry seasons; Treat: the treatment period (before: pretreatment, or after: the combined treatment and posttreatment); Int: the interaction term between precipitation and treatment period during the first year of growth or while in utero; Weight: body weight (dressed weight) corrected for age using the residuals. Bold values in the confidence interval (CI) column represent parameters that did not overlap zero.

\begin{tabular}{lcccc}
\hline Model parameter & Estimate & Std. error & Adjusted SE & $85 \%$ CI \\
\hline Intercept) & 17.9262 & 4.6458 & 4.6528 & 8.6492 to 27.2305 \\
Tem_grow_W & $-\mathbf{0 . 4 1 9 9}$ & $\mathbf{0 . 1 1 7 6}$ & $\mathbf{0 . 1 1 7 9}$ & $-\mathbf{0 . 6 5 7 7}$ to $-\mathbf{0 . 1 6 6 9}$ \\
Harv_yr_T_D & $-\mathbf{0 . 5 8 7 5}$ & $\mathbf{0 . 1 6 6 1}$ & $\mathbf{0 . 1 6 6 4}$ & $-\mathbf{0 . 9 1 6 8}$ to $-\mathbf{0 . 2 5 6 5}$ \\
Harv_yr_T_W & $-\mathbf{0 . 0 7 9 8}$ & $\mathbf{0 . 0 2 5 3}$ & $\mathbf{0 . 0 2 5 4}$ & $-\mathbf{0 . 1 3 0 5}$ to $-\mathbf{0 . 0 2 8 9}$ \\
Weight & $\mathbf{0 . 1 2 9 5}$ & $\mathbf{0 . 0 1 0 7}$ & $\mathbf{0 . 0 1 0 7}$ & $\mathbf{0 . 1 0 8 0}$ to $\mathbf{0 . 1 5 0 2}$ \\
Tem_in_utero & -0.2094 & 0.1272 & 0.1275 & -0.4677 to 0.0466 \\
Treat_in_utero & 0.6683 & 0.2820 & 0.2827 & -0.1830 to 1.3319 \\
Precip_grow_D & 0.0058 & 0.0029 & 0.0029 & -0.0015 to 0.0131 \\
Treat_grow [after] & 1.3187 & 0.6142 & 0.6150 & -0.3815 to 2.6159 \\
Precip_grow_W & 0.0001 & 0.0003 & 0.0003 & -0.0005 to 0.0007 \\
Int_treat_grow [after]_\&_precip_W & $-\mathbf{0 . 0 0 1 1}$ & $\mathbf{0 . 0 0 0 4}$ & $\mathbf{0 . 0 0 0 4}$ & $-\mathbf{0 . 0 0 1 9}$ to $-\mathbf{0 . 0 0 0 3}$ \\
Harv_yr_P_W & 0.0003 & 0.0003 & 0.0003 & -0.0002 to 0.0009 \\
Precip_in_utero & -0.0001 & 0.0002 & 0.0002 & -0.0006 to 0.0003 \\
Tem_grow_D & -0.0569 & 0.1437 & 0.1441 & -0.3785 to 0.2415 \\
\hline
\end{tabular}

Common conditions experienced by a cohort can result in distinguishable differences in phenotype when compared with other cohorts of the same age [31, 62, 63]. Therefore, identifying the long-term effects of environmental factors during early stages of life is critical to understanding patterns of growth and reproduction in populations of large herbivores $[10,60]$. Unfortunately, the interaction between weather and population density is not always well understood [58].
Even on an optimal diet, offspring originally from an area with high population density and low resource availability exhibited suppressed growth for 1 generation in domestic sheep (Ovis aries) [64] and did not recover until 2 generations in white-tailed deer (Odocoileus virginianus) [3]. In whitetailed deer, survival was directly related to the body condition of the mother during the previous two winters [65]. In contrast, other studies have reported that deer were able 
to recover from periods of poor nutrition and overcome cohort effects [66-68]. Consequently, understanding how a cohort can be affected by weather or population density has immense implications for the management and conservation of ungulates.

We were able to construct models for predicting body and antler size in male black-tailed deer living in a Mediterranean ecosystem. Our research offers new insights into the interaction between extrinsic and intrinsic factors, and effects of maternal and postnatal conditions on overall size of males at time of harvest. Biologists can evaluate effects of harvest on trends of antler size in relation to extrinsic factors during gestation by the mother and the first year of growth of male deer. Even minor changes in quality and availability of forage have resulted in relatively large fluctuations in rate of parturition and recruitment of young, because of the high energetic requirements necessary for gestation and lactation [60, 69-72]. In cervids, a cohort-wide decrease in body mass could have lasting consequences, affecting the reproductive performance of a population, because of the close association between size of males and reproductive success [8, 73-75]. We have created a valuable model for understanding and examining effects of population density in a variable climate. Moreover, our study provides additional information about interactions between extrinsic and intrinsic factors in large mammalian herbivores and its effects on antler size $[25,26$, $29,44,67,76,77]$. Our research is crucial for understanding the role of environmental factors in studies on body size and size of horn-like structures in relation to harvest of males $[78,79]$. In addition to considering effects of harvest on the size of horn-like structures, our research demonstrates that density-dependent influences and cohort effects need to be taken into account. Indeed, there is increasing evidence that density-dependent mechanisms may override beneficial and detrimental effects of climate $[11,31,58]$.

\section{Conflict of Interests}

The authors declare that there is no conflict of interests regarding the publication of this paper.

\section{Acknowledgments}

The authors thank many individuals that helped collect data during the initial study and were already acknowledged in McCullough (2001). For this study, the authors thank Z. Simpson for data processing and D. M. Walcott and K. M. Stewart for helpful reviews of their paper.

\section{References}

[1] B.-E. Sæther, "Environmental stochasticity and population dynamics of large herbivores: a search for mechanisms," Trends in Ecology and Evolution, vol. 12, no. 4, pp. 143-147, 1997.

[2] M. D. Pitt and H. F. Heady, "Responses of annual vegetation to temperature and rainfall patterns in Northern California," Ecology, vol. 59, no. 2, pp. 336-350, 1978.

[3] K. L. Monteith, L. E. Schmitz, J. A. Jenks, J. A. Delger, and R. T. Bowyer, "Growth of male white-tailed deer: consequences of maternal effects," Journal of Mammalogy, vol. 90, no. 3, pp. 651660, 2009.

[4] J. O. Ogutu and N. Owen-Smith, "ENSO, rainfall and temperature influences on extreme population declines among African savanna ungulates," Ecology Letters, vol. 6, no. 5, pp. 412-419, 2003.

[5] S. Bø and O. Hjeljord, "Do continental moose ranges improve during cloudy summers?” Canadian Journal of Zoology, vol. 69, no. 7, pp. 1875-1879, 1991.

[6] R. Langvatn, S. D. Albon, T. Burkey, and T. H. CluttonBrock, "Climate, plant phenology and variation in age of first reproduction in a temperate herbivore," Journal of Animal Ecology, vol. 65, no. 5, pp. 653-670, 1996.

[7] I. Herfindal, B.-E. Sæther, E. J. Solberg, R. Andersen, and K. A. Høgda, "Population characteristics predict responses in moose body mass to temporal variation in the environment," Journal of Animal Ecology, vol. 75, no. 5, pp. 1110-1118, 2006.

[8] E. J. Solberg, B.-E. Saether, O. Strand, and A. Loison, "Dynamics of a harvested moose population in a variable environment," Journal of Animal Ecology, vol. 68, no. 1, pp. 186-204, 1999.

[9] R. Aanes, B.-E. Sæther, and N. A. Øritsland, "Fluctuations of an introduced population of Svalbard reindeer: the effects of density dependence and climatic variation," Ecography, vol. 23, no. 4, pp. 437-443, 2000.

[10] J. G. Kie, R. T. Bowyer, and K. M. Stewart, "Ungulates in western coniferous forests: habitat relationships, population dynamics, and ecosystem processes," in Mammal Community Dynamics: Management and Conservation in the Coniferous Forests of Western North America, C. J. Zabel and R. G. Anthony, Eds., pp. 296-340, Cambridge University Press, Cambridge, UK, 2003.

[11] K. M. Stewart, R. T. Bowyer, B. L. Dick, B. K. Johnson, and J. G. Kie, "Density-dependent effects on physical condition and reproduction in North American elk: an experimental test," Oecologia, vol. 143, no. 1, pp. 85-93, 2005.

[12] T. H. Clutton-Brock, M. Major, and F. E. Guinness, "Population regulation in male and female red deer," The Journal of Animal Ecology, vol. 54, no. 3, pp. 831-846, 1985.

[13] H. D. Picton, "Climate and the prediction of reproduction of three ungulate species," Journal of Applied Ecology, vol. 21, no. 3, pp. 869-879, 1984.

[14] E. Post, N. C. Stenseth, I. Rolf, and J.-M. Fromentin, "Global climate change and phenotypic variation among red deer cohorts," Proceedings of the Royal Society of London B: Biological Sciences, vol. 264, no. 1386, pp. 1317-1324, 1997.

[15] E. Post and N. C. Stenseth, "Climatic variability, plant phenology, and northern ungulates," Ecology, vol. 80, no. 4, pp. 13221339, 1999.

[16] M. C. Forchhammer, T. H. Clutton-Brock, J. Lindström, and S. D. Albon, "Climate and population density induce long-term cohort variation in a northern ungulate," Journal of Animal Ecology, vol. 70, no. 5, pp. 721-729, 2001.

[17] E. Richard, S. E. Simpson, S. A. Medill, and P. D. Mcloughlin, "Interacting effects of age, density, and weather on survival and current reproduction for a large mammal," Ecology and Evolution, vol. 4, no. 19, pp. 3851-3860, 2014.

[18] J. Bernardo, "Maternal effects in animal ecology," American Zoologist, vol. 36, no. 2, pp. 83-105, 1996.

[19] M. Festa-Bianchet and J. T. Jorgenson, "Selfish mothers: reproductive expenditure and resource availability in bighorn ewes," Behavioral Ecology, vol. 9, no. 2, pp. 144-150, 1998. 
[20] S. D. Albon, T. H. Clutton-Brock, and F. L. Guinness, "Early development and population dynamics in red deer. II. Densityindependent effects and cohort variation," Journal of Animal Ecology, vol. 56, no. 1, pp. 69-81, 1987.

[21] J. M. Gaillard, D. Delorme, and J. M. Jullien, "Effects of cohort, sex, and birth date on body development of roe deer (Capreolus capreolus) fawns," Oecologia, vol. 94, no. 1, pp. 57-61, 1993.

[22] M. A. Keech, R. D. Boertje, R. T. Bowyer, and B. W. Dale, "Effects of birth weight on growth of young moose: do lowweight neonates compensate?" Alces, vol. 35, pp. 51-58, 1999.

[23] M. A. Keech, R. T. Bowyer, J. M. Ver Hoef, R. D. Boertje, B. W. Dale, and T. R. Stephenson, "Life-history consequences of maternal condition in Alaskan moose," The Journal of Wildife Management, vol. 64, no. 2, pp. 450-462, 2000.

[24] S. D. Côté and M. Festa-Bianchet, "Birthdate, mass and survival in mountain goat kids: effects of maternal characteristics and forage quality," Oecologia, vol. 127, no. 2, pp. 230-238, 2001.

[25] K. T. Schmidt, A. Stien, S. D. Albon, and F. E. Guinness, "Antler length of yearling red deer is determined by population density, weather and early life-history," Oecologia, vol. 127, no. 2, pp. 191197, 2001.

[26] E. D. Freeman, R. T. Larsen, K. Clegg, and B. R. McMillan, "Long-lasting effects of maternal condition in free-ranging cervids," PLoS ONE, vol. 8, no. 3, Article ID e58373, 2013.

[27] S. Hamel, J.-M. Gaillard, M. Festa-Bianchet, and S. D. Côté, "Individual quality, early-life conditions, and reproductive success in contrasted populations of large herbivores," Ecology, vol. 90, no. 7, pp. 1981-1995, 2009.

[28] L. D. Mech, M. E. Nelson, and R. E. McRoberts, "Effects of maternal and grandmaternal nutrition on deer mass and vulnerability to wolf predation," Journal of Mammalogy, vol. 72, no. 1, pp. 146-151, 1991.

[29] M. N. Clements, T. H. Clutton-Brock, S. D. Albon, J. M. Pemberton, and L. E. B. Kruuk, "Getting the timing right: antler growth phenology and sexual selection in a wild red deer population," Oecologia, vol. 164, no. 2, pp. 357-368, 2010.

[30] R. M. Sibly, W. Zuo, A. Kodric-Brown, and J. H. Brown, "Rensch's rule in large herbivorous mammals derived from metabolic scaling," American Naturalist, vol. 179, no. 2, pp. 169177, 2012.

[31] D. R. McCullough, "Male harvest in relation to female removals in a black-tailed deer population," The Journal of Wildlife Management, vol. 65, no. 1, pp. 46-58, 2001.

[32] A. H. Murphy and M. F. Heady, "Vascular plants of the Hopland Field Station, Mendocino County, California," Wasmann Journal of Biology, vol. 41, no. 1-2, pp. 53-96, 1983.

[33] M. M. Conner, M. M. Jaeger, T. J. Weller, and D. R. McCullough, "Effect of coyote removal on sheep depredation in northern California," Journal of Wildlife Management, vol. 62, no. 2, pp. 690-699, 1998.

[34] R. C. Team, R: A Language and Environment for Statistical Computing. R Foundation for Statistical Computing, Vienna, Austria, 2012, Foundation for Statistical Computing, Vienna, Austria, 2014.

[35] K. Aho, Asbio: A Collection of Statistical Tools for Biologists, CRAN, 2014.

[36] R. D. Cameron and D. B. Stone, "To weigh or to mass? The question is in the balance," Wildlife Society Bulletin, vol. 23, no. 1, p. 109, 1995.

[37] A. E. Anderson, D. E. Medin, and D. C. Bowden, "Growth and morphometry of the carcass, selected bones, organs, and glands of mule deer," Wildlife Monographs, no. 39, pp. 3-122, 1974.
[38] D. R. McCullough and P. Beier, "Upper vs. Lower molars for cementum annuli age determination of deer," The Journal of Wildlife Management, vol. 50, no. 4, pp. 705-706, 1986.

[39] D. C. Thomas and P. J. Bandy, "Accuracy of dental-wear age estimates of black-tailed deer," The Journal of Wildlife Management, vol. 39, no. 4, pp. 674-678, 1975.

[40] D. P. Swain, "A problem with the use of meristic characters to estimate developmental stability," The American Naturalist, vol. 129, no. 5, pp. 761-768, 1987.

[41] K. M. Stewart, R. T. Bowyer, J. G. Kie, and W. C. Gasaway, "Antler size relative to body mass in moose: tradeoffs associated with reproduction," Alces, vol. 36, pp. 77-84, 2000.

[42] R. T. Bowyer, K. M. Stewart, J. G. Kie, and W. C. Gasaway, "Fluctuating asymmetry in antlers of Alaskan moose: size matters," Journal of Mammalogy, vol. 82, no. 3, pp. 814-824, 2001.

[43] R. J. Goss, Deer Antlers, Regeneration, Evolution and Function, Academic Press, New York, NY, USA, 1983.

[44] C. Vanpé, J.-M. Gaillard, P. Kjellander et al., "Antler size provides an honest signal of male phenotypic quality in roe deer," The American Naturalist, vol. 169, no. 4, pp. 481-493, 2007.

[45] G. A. Nelson, Fishmethods: Fishery Science Methods and Models in R, CRAN, 2014.

[46] A. J. Fabens, "Properties and fitting of the von bertalanffy growth curve," Growth, Development and Aging, vol. 29, no. 3, pp. 265-289, 1965.

[47] E. M. Zullinger, R. E. Ricklefs, K. H. Redford, and G. M. Mace, "Fitting sigmoidal equations to mammalian growth curves," Journal of Mammalogy, vol. 65, no. 4, pp. 607-636, 1984.

[48] H. Walter and E. Box, "Global classification of natural terrestrial ecosystems," Vegetatio, vol. 32, no. 2, pp. 75-81, 1976.

[49] P. J. Pekins, K. S. Smith, and W. W. Mautz, "The energy cost of gestation in white-tailed deer," Canadian Journal of Zoology, vol. 76, no. 6, pp. 1091-1097, 1998.

[50] R. T. Bowyer, "Timing of parturition and lactation in southern mule deer," Journal of Mammalogy, vol. 72, no. 1, pp. 138-145, 1991.

[51] J. Fox and S. Weisberg, An R Companion to Applied Regression, Sage, Thousand Oaks, Calif, USA, 2010.

[52] K. Aho, Foundational and Applied Statistics for Biologists Using $R$, CRC Press, Boca Raton, Fla, USA, 2014.

[53] K. Barton, MuMIn: Multi-Model Inference, CRAN, 2014.

[54] K. P. Burnham and D. R. Anderson, Model Selection and Multimodel Inference: A Practical Information-Theoretic Approach, Springer Science \& Business Media, New York, NY, USA, 2nd edition, 2002.

[55] T. W. Arnold, "Uninformative parameters and model selection using akaike's information criterion," The Journal of Wildlife Management, vol. 74, no. 6, pp. 1175-1178, 2010.

[56] W. J. Conover, Practical Nonparametric Statistics, Texas Tech University, Lubbock, Tex, USA; John Wiley \& Sons, New York, NY, USA, 2nd edition, 1980.

[57] R. F. Dasmann and R. D. Taber, "Behavior of Columbian blacktailed deer with reference to population ecology," Journal of Mammalogy, vol. 37, no. 2, pp. 143-164, 1956.

[58] R. T. Bowyer, C. B. Vernon, M. K. Stewart, C. J. Whiting, and L. K. Monteith, "Density dependence in ungulates: a review of causes, and concepts with some clarifications," California Fish and Game, vol. 100, no. 3, pp. 550-572, 2014.

[59] B. M. Pierce, V. C. Bleich, K. L. Monteith, and R. T. Bowyer, "Top-down versus bottom-up forcing: evidence from mountain 
lions and mule deer," Journal of Mammalogy, vol. 93, no. 4, pp. 977-988, 2012.

[60] K. L. Monteith, V. C. Bleich, T. R. Stephenson et al., "Life-history characteristics of mule deer: effects of nutrition in a variable environment," Wildlife Monographs, vol. 186, no. 1, pp. 1-62, 2014.

[61] D. R. McCullough, "Failure of the tooth cementum aging technique with reduced population density of deer," Wildlife Society Bulletin, vol. 24, no. 4, pp. 722-724, 1996.

[62] A. Beckerman, T. G. Benton, E. Ranta, V. Kaitala, and P. Lundberg, "Population dynamic consequences of delayed life-history effects," Trends in Ecology \& Evolution, vol. 17, no. 6, pp. 263-269, 2002.

[63] M. Douhard, J.-M. Gaillard, D. Delorme et al., "Variation in adult body mass of roe deer: early environmental conditions influence early and late body growth of females," Ecology, vol. 94, no. 8, pp. 1805-1814, 2013.

[64] R. Mobæk, A. Mysterud, Ø. Holand, and G. Austrheim, “Temporal variation in density dependent body growth of a large herbivore," Oikos, vol. 122, no. 3, pp. 421-427, 2013.

[65] L. D. Mech, R. E. McRoberts, R. O. Peterson, and R. E. Page, "Relationship of deer and moose populations to previous winters' snow," The Journal of Animal Ecology, vol. 56, no. 2, pp. 615-627, 1987.

[66] B. K. Strickland, S. Demarais, and P. D. Gerard, "Variation in mass and lactation among cohorts of white-tailed deer Odocoileus virginianus," Wildlife Biology, vol. 14, no. 2, pp. 263-271, 2008.

[67] K. L. Gee, S. L. Webb, and P. D. Jones, "Age-specific changes in body mass and delayed physical development of a known-aged sample of wild, white-tailed deer," Wildlife Biology in Practice, vol. 10, no. 2, pp. 69-84, 2014.

[68] D. M. Wolcott, J. Asmus, and F. W. Weckerly, "Overcoming cohort effects in a Mediterranean ecosystem: the role of density and precipitation on southern mule deer body mass," The Journal of Wildlife Management, vol. 78, no. 8, pp. 1335-1342, 2014.

[69] R. G. White, "Foraging patterns and their multiplier effects on productivity of northern ungulates," Oikos, vol. 40, no. 3, pp. 377-384, 1983.

[70] E. A. Lenart, R. T. Bowyer, J. Ver Hoef, and R. W. Ruess, "Climate change and caribou: effects of summer weather on forage," Canadian Journal of Zoology, vol. 80, no. 4, pp. 664-678, 2002.

[71] R. C. Cook, D. L. Murray, J. G. Cook, P. Zager, and S. L. Monfort, "Nutritional influences on breeding dynamics in elk," Canadian Journal of Zoology, vol. 79, no. 5, pp. 845-853, 2001.

[72] K. L. Monteith, T. R. Stephenson, V. C. Bleich, M. M. Conner, B. M. Pierce, and R. T. Bowyer, "Risk-sensitive allocation in seasonal dynamics of fat and protein reserves in a long-lived mammal," Journal of Animal Ecology, vol. 82, no. 2, pp. 377-388, 2013.

[73] R. T. Bowyer, "Antler characteristics as related to social status of male southern mule deer," The Southwestern Naturalist, vol. 31, no. 3, pp. 289-298, 1986.

[74] T. H. Clutton-Brock, M. Major, S. D. Albon, and F. E. Guinness, "Early development and population dynamics in red deer. I. Density-dependent effects on juvenile survival," The Journal of Animal Ecology, vol. 56, no. 1, pp. 53-67, 1987.

[75] E. J. Solberg, A. Loison, J.-M. Gaillard, and M. Heim, "Lasting effects of conditions at birth on moose body mass," Ecography, vol. 27, no. 5, pp. 677-687, 2004.
[76] C. Azorit, M. Analla, R. Carrasco, and J. Muñoz-Cobo, "Influence of age and environment on antler traits in Spanish red deer (Cervus elaphus hispanicus)," Zeitschrift für Jagdwissenschaft, vol. 48, no. 3, pp. 137-144, 2002.

[77] R. B. Weladji, Ø. Holand, G. Steinheim, J. E. Colman, H. Gjøstein, and A. Kosmo, "Sexual dimorphism and intercorhort variation in reindeer calf antler length is associated with density and weather," Oecologia, vol. 145, no. 4, pp. 549-555, 2005.

[78] M. Festa-Bianchet and R. Lee, "Guns, sheep and genes: when and why trophy hunting may be a selective pressure," in Recreational Hunting, Conservation and Rural Livelihoods: Science and Practice, pp. 97-107, Wiley-Blackwell, Oxford, UK, 2009.

[79] K. L. Monteith, R. A. Long, V. C. Bleich, J. R. Heffelfinger, P. R. Krausman, and R. T. Bowyer, "Effects of harvest, culture, and climate on trends in size of horn-like structures in trophy ungulates," Wildlife Monographs, vol. 183, no. 1, pp. 1-28, 2013. 

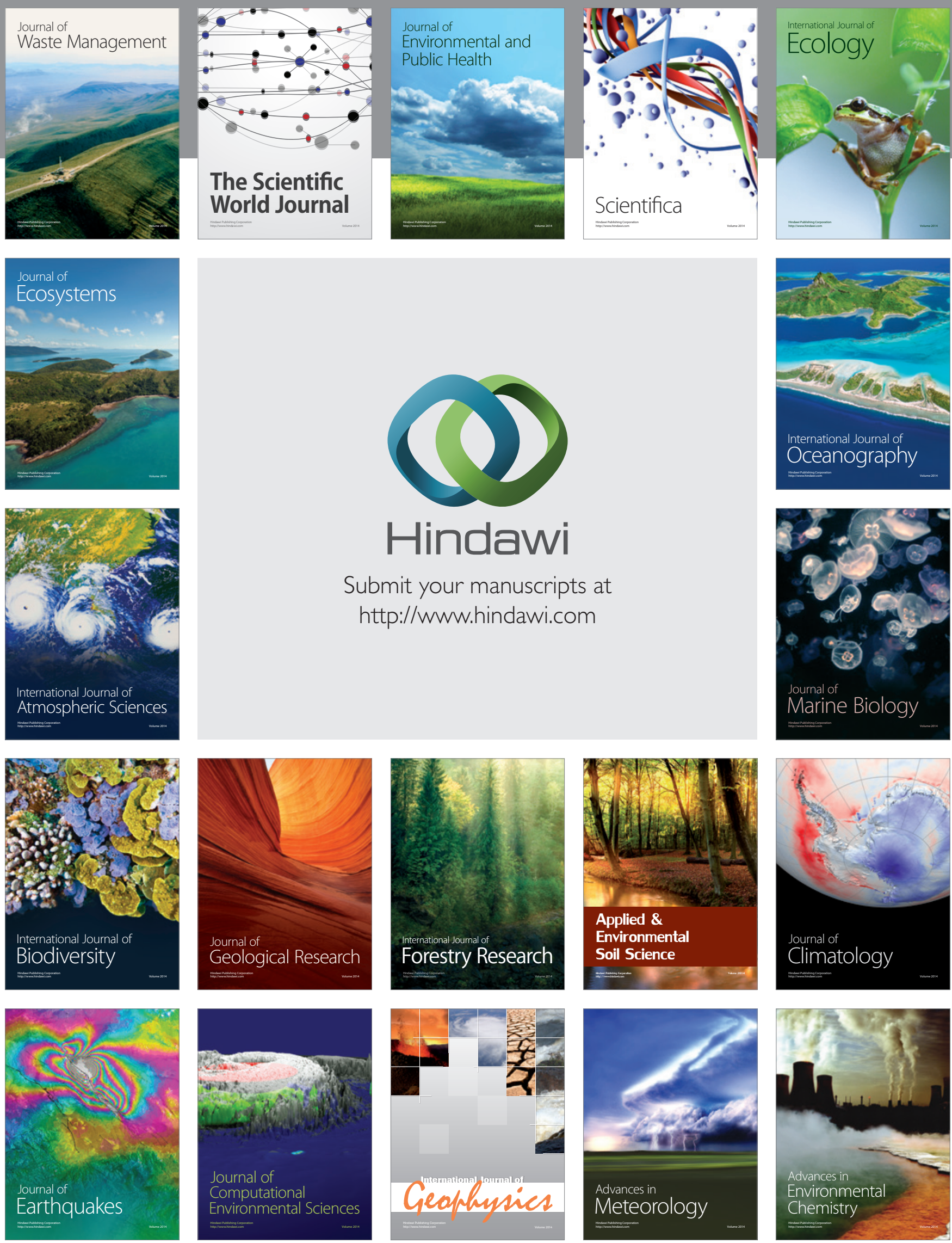